\title{
AS OLIMPÍADAS BRASILEIRA DE MATEMÁTICA DAS ESCOLAS PÚBLICAS NA FORMAÇÃO DE PROFESSORES E ALUNOS
}

\author{
Carlas Ciane Silva CALDAS ${ }^{1}$ \\ Campus Universitário de Abaetetuba/UFPA \\ cciane@yahoo.com.br \\ Cléber Soares VIANA² \\ Campus Universitário de Abaetetuba/UFPA \\ csoaresviana@bol.com.br
}

Resumo: O referido artigo tem como objetivo abordar as OBMEPS (Olimpíadas Brasileiras de Matemática das Escolas Públicas); falaremos também da origem histórica das Olimpíadas da Matemática, e como abordagem final comentaremos de que forma as OBMEPS têm contribuído para a formação de alunos e professores nas Escolas Públicas das regiões Nordeste (Ceará), Sudeste (Minas-Gerais) e Norte, especificamente nos Municípios de Barcarena e Parauapebas.

Palavras-chave: Matemática. Olimpíada. Formação. Educação.

Abstrat: Abstrat:The related article has as objective to embroider the OBMEPS (Olimpiadas Brazilian of Mathematics of the Public Schools); we will also speak of the historical origin of the Olimpiadas of the Mathematics, and as boarding final we will comment of that it forms the OBMEPS has contributed for a formation of pupils and professors in the Public Schools of the regions Northeast (Ceará), Southeast (Mine-Generality) and North, specifically in the Cities of Barcarena and Parauapebas.

Keywords: Mathematics. Olimpiada. Formation. Education.

\footnotetext{
${ }^{1}$ Acadêmica do Curso de Licenciatura Plena em Matemática da UFPA e ex-bolsista do Programa Conexões de Saberes: diálogos entre a universidade e as comunidades populares.

${ }^{2}$ Acadêmico do Curso de Licenciatura Plena em Matemática da UFPA e ex-bolsista da OBMEP.
} 


\section{Introdução}

A Matemática é uma ciência viva e que não está apenas inserida no cotidiano dos cidadãos, mas também nas Universidades e nos Centros de Pesquisas, onde se verifica hoje uma impressionante produção de novos conhecimentos que, a par de seus valores intrínsecos, de natureza lógica, tem sido instrumentos úteis na solução de problemas científicos, tecnológicos e sociais. Esta ciência caracteriza-se como uma forma de compreender e atuar no mundo. $\mathrm{O}$ conhecimento gerado nessa área do saber é fruto da construção humana e da sua interação constante com o contexto em que está inserido.

A Matemática começou por ser "a ciência que estuda, por meio do raciocínio dedutivo, as propriedades dos entes abstratos (números, figuras geométricas, funções, espaços etc.) bem como as relações que se estabelecem entre eles" (Grande Dicionário Larousse Cultural, 1999, p. 600). Desse modo, as matemáticas são ferramentas especialmente adaptadas aos tratados das noções abstratas de qualquer natureza e, neste domínio, o seu poder é ilimitado. Essa ciência formal está baseada em axiomas $^{3}$, teoremas ${ }^{4}$, corolários ${ }^{5}$, lemas ${ }^{6}$, postulados e proposições $^{8}$ para chegar a conclusões teóricas e práticas. Ela também pode ser vista como um sistema formal de pensamento para reconhecer, classificar e explorar padrões.

A Olimpíada Brasileira de Matemática das Escolas Públicas vem sendo uma das contribuidoras para esses novos rumos em relação à tão temida "Matemática", prova disso são os trabalhos desenvolvidos nos estados do Ceará, Minas Gerais e Pará, especificamente no município

${ }^{3}$ Axioma: proporção que se admite como verdadeira porque dela é possível deduzir as proposições de uma teoria ou de um sistema lógico ou matemático.

${ }^{4}$ Teorema: proporções que para ser admitida ou se tornar evidente necessita de demonstração.

${ }^{5}$ Corolário: proposição que imediatamente se deduz de outra demonstrada como consequência ou resultado.

${ }^{6}$ Lema: proposição que prepara a demonstração de outra.

${ }^{7}$ Postulado: proposição não evidente e nem demonstrável que se admite como princípio de um sistema dedutível, de uma operação lógica ou de um sistema de normas práticas.

${ }^{8}$ Proposição: aquilo que se propõe, assunto que vai se discutir ou asserção que vai defendida como verdadeira ou falsa. 
de Barcarena e Parauapebas. Com esse campeonato, alunos e professores vêm se desempenhando e mostrando um novo papel na sociedade. Esta competição vem quebrando, portanto, com velhos tabus dentro desta sociedade onde a matemática deixa de estar centrada no professor, ou seja, onde este conhecimento deixa de estar "centralizado" e passa a ser de todos aqueles que fazem parte desse processo educacional.

\section{O que é uma Olimpíada de Matemática?}

As Olimpíadas de Matemática podem ser definidas como uma competição equivalente às esportivas e, assim como toda competição, tem sua preparação específica, na qual os "atletas" são os alunos e seus "técnicos" são os professores. Essa preparação dos "atletas" consiste na solução de problemas de Matemática individual ou em grupo. Eles "treinam" com o objetivo de desenvolver a habilidade lógica, a criatividade e a sociabilidade, bem como desenvolver bons métodos de pensamento e de trabalho.

\subsection{História da $1^{\text {a }}$ Olimpíada de Matemática}

As primeiras competições de Matemática realizadas em nível nacional, foram os concursos de Eotvos, na Hungria, em 1894. Neste ano, a sociedade de Matemática e Física deste país promoveu esta competição, quando foi realizada uma prova envolvendo todos os alunos concluintes do segundo grau no país, em homenagem a um famoso professor de matemática, membro da Academia de Ciência Húngara e do Instituto politécnico da Universidade de Budapeste Jósef Kürschák, onde este evento foi um sucesso. Por isso, essa ideia construtiva foi disseminada pelo resto da Europa e para todo mundo e passou a ser realizada todos os anos.

Esse acontecimento matemático foi realizado durante a publicação do documento chamado Carta Olímpica de 1894, que é a codificação dos princípios fundamentais do Olimpismo, regras e regulamentos adotados pelo Comitê Olímpico Internacional (COI). Foi exatamente durante essa efervescência de fins do século XIX, da qual originou também o processo iniciado pelo Barão de Coubertin, que levou à realização das primeiras Olimpíadas da época moderna em Atenas, em 1896. 
O Barão de Coubertin ficou conhecido por ter usado uma frase pronunciada pelo bispo Ethelbert Talbot, na Catedral Londrina de Saint Paul, em um ato religioso antes dos jogos de 1908, que foi realizado em Londres: "O importante não é vencer, mas competir. E com dignidade". Pode-se dizer que esse acontecimento nesta década foi mais um grande salto na área das ciências exatas e que através do mesmo abriram-se caminhos para uma nova aprendizagem neste ramo da ciência.

\subsection{História da Olimpíada Internacional de Matemática}

A Olimpíada Internacional de Matemática (IMO) é realizada todos os anos em um país sede diferente. Sendo que a primeira Olimpíada foi realizada na Romênia, na cidade de Brasov, em 1959, com sete países participantes, tendo a participação de 52 pessoas; foi neste mesmo ano que a Olimpíada de Matemática tornou-se competição. Esse evento é um dos mais importantes realizados na área de Matemática. E ao longo dos anos, esse acontecimento expandiu-se para mais de 90 países, nos cinco continentes, e cujos representantes são formados por Equipe de até seis participantes do Ensino Médio, ou que não tenha ingressado na Universidade, ou equivalente na data da celebração do evento. De 1959 até 2008 já foram realizadas 49 Olimpíadas. Em 2009 a 50ª Olimpíada será realizada na Alemanha, na cidade de Bromem.

\subsection{História da Olimpíada de Matemática no Brasil}

No Brasil, a primeira Olimpíada de Matemática foi a Olimpíada Paulista de Matemática, realizada em 1977, pela Academia de Ciências do Estado de São Paulo. Dois anos mais tarde surgiu a Olimpíada Brasileira de Matemática (OBM), organizada pela Sociedade Brasileira de Matemática (SBM).

AOBM, em conjunto com as Olimpíadas Regionais de Matemática, envolve anualmente a participação de cerca de 200 mil estudantes no Brasil. Esse envolvimento da OBM com as Olimpíadas Regionais de Matemática tem como objetivo selecionar os alunos que vão representar o Brasil nas diversas Olimpíadas Internacionais (Internacional, IberoAmericano etc.) que são disputadas. A OBM teve vários formatos ao 
longo dos anos. De 1979 até 1989 era disputada em uma única fase (uma prova contendo cinco ou seis questões discursivas) e não eram separadas por níveis, fazendo com que seus premiados fossem todos do Ensino Médio (na época chamava-se de segundo grau). Em 1990, a OBM passou a ser realizada em duas fases (uma primeira fase em 20 ou 25 questões discursivas) e em dois níveis: OBM Sênior (alunos do Ensino Médio) e OBM Jr. (alunos do Ensino Fundamental, menos alunos da $5^{\mathrm{a}}$ série).

A partir do ano de 1998, houve outras alterações no formato da Olimpíada Brasileira de Matemática, e esta ficou bastante diferente da que vinha sendo praticada nos últimos anos. Isto porque passou a atingir os alunos desde a $5^{a}$ série do ensino fundamental. Antes, a OBM era principalmente um instrumento para detectar talentos e desenvolvê-los, mas, agora, tem também por objetivo promover em âmbito nacional a melhoria do ensino de Matemática nas escolas, com o desenvolvimento conjunto de alunos e professores. A Olimpíada Brasileira de Matemática, desde 1998, deixou de ser apenas uma competição para ser um novo método de auxílio ao ensino no Brasil.

\subsection{História da Olimpíada Brasileira de Matemática nas Escolas Públicas}

A primeira Olimpíada de Matemática nas Escolas Públicas (OBMEP) foi lançada oficialmente no dia 19 de maio de 2005, em Brasília, pelo presidente da República, Luiz Inácio Lula da Silva, e os ministros da Ciência e Tecnologia, Eduardo Campos, e da Educação, Tarso Genro. Essa $1^{\text {a }}$ competição mobilizou escolas públicas de todo o país, pois 10,5 milhões de jovens inscreveram-se. Observa-se através dos números de inscritos que esse evento é um dos maiores do gênero no mundo, superando em número de inscrição da Olimpíada de Matemática realizada nos Estados Unidos, que reúne em média 6 milhões de alunos a cada ano. A OBMEP é uma competição de iniciativa inédita porque é direcionada especificamente às escolas públicas de todo o país.

A Olimpíada de Matemática é um canal de inclusão social, uma vez que propicia o descobrimento de talentos, inclusive entre os mais carentes, gente que nunca teve uma oportunidade, e que agora passam a

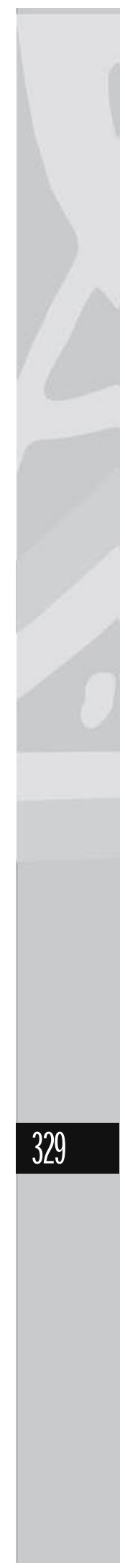


dispor dos meios mínimos para avançar numa carreira com melhores perspectivas (CAMPUS, 2005, p. 4)9.

A OBMEP tem servido como grande incentivo ao estudo da Matemática e também para uma maior reflexão sobre a educação pública em nosso País, além de propiciar a aproximação entre universidades públicas, institutos de pesquisa e sociedades científicas com as escolas públicas, bem como o envolvimento das Secretarias Estaduais e Municipais de Educação e de Ciência e Tecnologia, cujo apoio vem sendo fundamental para o sucesso do projeto. Os estudantes que participam deste evento vêm tanto dos grandes quanto dos pequenos centros, de zonas rurais, de comunidades indígenas, comunidades remanescente de quilombolas e assentamentos. Também participam deficientes visuais, auditivos e motores. A OBMEP é promovida pelo governo federal, por meio dos Ministérios da Ciência e Tecnologia (MCT) e do Ministério da Educação (MEC), e realizada pelo Instituto de Matemática Aplicada (IMPA/MCT) e a Sociedade Brasileira de Matemática (SBM). Este trabalho tem com um dos seus objetivos valorizar os estudantes e os professores, assim como suas escolas, suas cidades e seus estados.

Desde o início deste projeto, é possível notar uma participação expressiva do número de alunos a cada ano de competição, assim como seus resultados. Como citado acima, a primeira Olimpíada de Matemática teve uma participação considerável, mostraremos então como vem se desenvolvendo essa competição desde a sua primeira edição, realizada em 2005 até 2008.

A $1^{\text {a }}$ Olimpíada Brasileira de Matemática das Escolas Públicas, realizada 2005, inscreveram-se 10,5 milhões de alunos, superando a meta prevista que era de 5 milhões, alcançando 31 mil escolas de 5 mil municípios. Já a $2^{\mathrm{a}}$, em 2006, contou com mais de 14 milhões de estudantes em todo o país, representando um aumento de quase 35\% em relação ao ano de 2005. Nesta edição, todos os estados brasileiros participaram, com mais de 32 mil escolas.

\footnotetext{
${ }^{9}$ Eduardo Campus Ministro da Ciência e Tecnologia no ano de 2005; durante o seu ministério teve início a primeira Olimpíada Brasileira de Matemática das Escolas Públicas (Cf. Jornal C\&T, 2005, p. 4).
} 
Em 2007, a $3^{\text {a }}$ OBMEP contou com 17.271.849 inscritos, representando um aumento de $22 \%$ em relação a 2006 . Esta edição contou com a participação voluntária de 120 mil professores de matemática e de outras disciplinas em todo o País. Eles são os responsáveis pela aplicação e correção das provas da primeira fase da competição, e classificam para segunda fase apenas $5 \%$ dos alunos participantes. Na 4 a edição em 2008 , foram inscritos 18.317 .729 alunos, o que significa a participação de $10 \%$ da população brasileira. Esse número de inscritos representa um milhão a mais de participantes na olimpíada, em relação ao ano de 2007.

Nesta $4^{a}$ OBMEP, 40 mil escolas fizeram a inscrição (contra 38,5 mil escolas em 2007), o que significa a participação de $72 \%$ das escolas públicas do Brasil e adesão de 98,7\% dos municípios brasileiros. Destacase dentre os estados participantes, o estado do Mato Grosso do Sul, onde $100 \%$ das escolas participam do processo.

A Olimpíada acontece sempre no mês de agosto e é dividida em três níveis e duas etapas. A primeira parte deste evento é uma avaliação com questões de múltipla escolha para todos os participantes. Já a segunda etapa consiste na aplicação de uma prova discursiva para os aprovados na primeira. Os organizadores deste evento acreditam que a Matemática - assim como o esporte - não é apenas uma habilidade ou conhecimento técnico, e sim, que ela pode ser uma atividade integrada, de inclusão social, e uma oportunidade de desenvolvimento pessoal a que deve ter acesso o maior número de crianças e jovens.

\section{O papel da OBMEP na formação de professores e alunos}

A Olimpíada Brasileira de Matemática das Escolas públicas (OBMEP) vai de encontro com as velhas técnicas tradicionais, onde o professor deixa de ser o detentor do saber e passa a ser o coordenador deste conhecimento, adaptando sua prática pedagógica aos novos tempos.

$\mathrm{O}$ século $\mathrm{XX}$ foi marcado pela discussão sobre a qualidade educacional e sobre as condições necessárias para assegurar o direito de crianças, jovens e adultos a aprendizagens imprescindíveis para o desenvolvimento de suas capacidades. Essa questão não é propriamente nova; entretanto, nos anos 90, a educação de qualidade tornou-se uma bandeira assumida mais ou menos por todos. Nos dias atuais, o governo 
federal tem elaborado vários projetos para que realmente se concretize esse direito; dentre eles destaca-se o da OBMEP.

Vivemos em tempo de globalização econômica, a qual tem influenciado de tal maneira a educação. A situação que se configura em razão desse processo de internacionalização da economia e de supremacia dos interesses do mercado tem contribuído para sentimentos nada construtivos - como o individualismo, a intolerância, a violência, dentre outros fatores que tem atingido o âmbito escolar. Verifica-se que essas transformações científicas e tecnológicas, que ocorrem de forma acelerada, exigem cada vez mais dos profissionais da educação, pois esse contexto coloca enormes desafios para os mesmos.

Falar em desafios, contextos é mostrar a necessidade de formar professores e alunos para a atual situação que se vivencia na educação. A Olimpíada de Matemática das escolas públicas, ao ser lançada, trouxe como objetivos ajudar educadores através de cursos de formação, que tem sido promovidos por algumas instituições de ensino superior, e estimular, desenvolver a autonomia, o raciocínio lógico-matemático do educando, contribuindo efetivamente para um bom desempenho escolar e para participação ativa na sociedade. Além disso, ela também visa diminuir os altos índices de reprovação em Matemática e a evasão nesta disciplina.

No entanto, entre as deficiências apontadas na crise do ensino, destaca-se a falta de tempo que muitos educadores alegam, levandoos a certos impedimentos, os quais não permitem que modifiquem sua prática pedagógica, tendo como referencial um plano que sane as dificuldades diárias. É esse obstáculo na vida desse profissional da educação, especificamente do professor de matemática, que nos faz viver em constante reflexão de quão grande problemática vem se tornando a aprendizagem, pois com a falta de planejamento esses educadores ministram essa disciplina de qualquer forma, contribuindo também para o descaso e o fracasso dessa ciência, na vida do educando.

Através de pesquisas realizadas é possível verificar um grande avanço, obtido em alguns Estados do país, no que se refere à formação destes profissionais e do alunado, como no caso do Ceará, onde se observa que a Olimpíada de Matemática é de fundamental importância, pois o Centro Federal de Educação Tecnológica do Ceará (CEFET/CE) tem desenvolvido este projeto com bastante êxito, em relação aos cursos que 
estão sendo ofertados aos educadores para aperfeiçoar a capacitação dos mesmos e melhorar a qualidade do ensino; já em relação ao educando, o mesmo através deste processo vem adquirindo habilidades tanto na área das exatas quanto em outras áreas do conhecimento.

Este projeto veio ajudar esta localidade a qual teve o reconhecimento satisfatório, nos anos de 2005 e 2006, com medalhas de ouro e menções honrosas, apesar desta ser uma região pobre onde a média nas disciplinas de matemática e de língua portuguesa alcança índices insipientes; a vantagem que as olimpíadas trouxeram para este local foi conseguir captar a atenção e interesse não só dos alunos mais preparados, mas fundamentalmente estimular e embasar os que apresentam baixo desempenho.

A proposta também destas atividades realizadas no CEFET/CE é trabalhar com o aluno de forma lúdica e prazerosa na construção do conhecimento, focando sua aplicação, ao trilhar por um caminho que ele mesmo tenta construir, onde faz inferências, levanta hipótese e tira suas conclusões de maneira independente, interagindo com outros colegas e professores; além disso, este projeto desmitifica a ideia de que a matemática é uma matéria difícil e que é para poucos principalmente aqueles que têm o poder nas mãos, pois "[...] desde o início, a produção e organização do conhecimento matemático estava nas mãos da classe dominante" (TENÓRIO, 1995 citado por SILVEIRA, 2005, 105).

Outro estado que tem desenvolvido com excelente desempenho este projeto, é o de Minas Gerais, que tem como parceira a Universidade Federal de Minas Gerais (UFMG), a qual, junto com o departamento de Matemática (professores e bolsistas) e comunidade de professores do ensino fundamental e médio, vem realizando este trabalho; o estado vem colaborando de forma significativa nesta experiência de intercâmbio de saberes e informações no qual se procura articular teoria e prática entre professores e futuros professores de matemática. $O$ trabalho que vem sendo realizado pelos professores e alunos desta instituição de ensino é de fundamental importância, pois ele vem utilizando formas e abordagens diferenciadas, tendo como objetivo comum colaborar para que educandos e educadores de matemática das escolas públicas possam refletir sobre formas alternativas para trabalhar esta disciplina no dia-a-dia da sala de aula.

É possível dizer que a educação vem trilhando um novo caminho através de novas informações e tecnologias, com desafios cada vez maiores 
e mais complexos, colocados por esta sociedade contemporânea; esta tem influenciado de alguma forma o desenvolvimento cognitivo dos alunos, e é importante dizer que as instituições de ensino superior, junto com os professores e a comunidade escolar, vêm buscando uma nova postura na forma de se trabalhar as Olimpíadas de Matemática.

É importante ressaltar que os professores devem ser antes de tudo mediadores e, sobretudo, motivadores daquilo que se quer ensinar, pois para ensinar algo a um aluno, este deve ter um motivo para aprender. É preciso que os professores trabalhem nesta motivação, com a finalidade de preparar e capacitar o aluno para participar de uma Olimpíada de Matemática dentre outras finalidades educacionais.

Outro fator de grande importância são as impressões que permeiam a mente do educando: a intuição. É preciso, portanto, melhorar essa intuição, depurá-la, para trabalhá-la num processo de construção em que este aluno por si só chegue a conclusões, em lugar de confiar apenas nas equações, valorizando sua bagagem cognitiva interior; o professor precisa respeitar o aluno como um ser social. O aluno não é tão somente o sujeito da aprendizagem, mas aquele que aprende junto a outras pessoas, colegas e professores o que o seu grupo social produz, tal como valores, linguagem e o próprio conhecimento. Contudo, o ser humano não aprende sozinho e, portanto, não se educa sozinho. Sua aprendizagem e a sua educação acontecem em um contexto social. Mas esse fato não quer dizer que a aprendizagem do ser humano é exclusiva $\mathrm{e}$ necessariamente produzida pela ação de terceiros, e que, portanto, outros o educam, pois "Ninguém educa Ninguém, Ninguém educa a si mesmo, os homens se educam entre si, mediatizados pelo mundo" (FREIRE, 1987, p. 39). Portanto, é nesse novo rumo que o educador tem um novo papel no processo de ensino-aprendizagem, se tornando um articulador do saber, deixando de ser o detentor do conhecimento e passando a desenvolvê-lo junto de seus alunos.

\subsection{Formação de professores e alunos e a realidade em alguns municípios do Pará}

A qualidade da educação básica está relacionada à melhoria de alguns importantes indicadores educacionais: o acesso (proporção de 
pessoas na escola), o fluxo (diminuição da reprovação e da evasão escolar), a formação de professores e a melhoria da aprendizagem do aluno.

As dificuldades encontradas na educação, especificamente na aprendizagem bem como as deficiências no ensino da Matemática constituem, já há algum tempo, um problema pedagógico; muitos estudiosos tem se preocupado e investigado as questões inerentes à aplicação de metodologias no ensino, especificamente da Matemática, assim como o refinamento da compreensão dessa ciência tão discriminada pela exatidão de seus métodos.

$\mathrm{Na}$ região Norte, especificamente no Pará, a realidade na aprendizagem da Matemática não é diferente de outras regiões, pois grande é o índice de reprovação e evasão que ocorre nessa área do saber, além do descaso com que muitos educadores tratam essa disciplina; por isso, para se conhecer a realidade, primeiramente é necessário conhecer a região em que está inserida e qual o seu contexto. De acordo com Rios, "[...] ao pretender lançar um olhar claro, fundo e longo sobre a educação a reflexão deve partir da situação, do contexto social que envolve essa educação. É esse contexto que a caracteriza que lhe confere especificidade" (2001, p. 29). Como é possível analisar, esta é a situação educacional do Pará em relação à problemática da educação do Brasil (aprovação, evasão e reprovação). Contudo, verifica-se que esta situação vem tentando melhorar, pois existem municípios no Pará, como Parauapebas e Barcarena, que desenvolveram e devolvem projetos na área da Matemática para que haja uma diminuição nessas dificuldades educacionais.

\subsubsection{A Realidade em Parauapebas}

Dentre os municípios do estado do Pará, Parauapebas tem avançado satisfatoriamente na estrutura educacional, considerando a diminuição na taxa de analfabetismo e também o avanço no ensino da Matemática, pois se observa que esta vem destacando-se no cenário nacional e regional, como participante da OBMEP, ficando ao lado de Belém, Marabá, Altamira e Rurópolis. É importante ressaltar que para os que fazem parte desse evento, a OBMEP é vista por todo o Brasil como termômetro e subsídio para traçar radiografia dos locais onde o ensino público vem melhorando. 
Através desse projeto, conseguiu-se estimular o ensino da Matemática nos alunos da cidade e, com isso, melhorando satisfatoriamente o ensino da mesma e de outras disciplinas; além disso, professores vêm recebendo orientações e cursos de capacitação para que possam se aperfeiçoar cada vez mais para o novo rumo que essa ciência tem tomado. Contudo, verifica-se também que educandos e educadores tem andado juntos nessa caminhada e com isso planejando metas que tem como finalidade criar um ambiente que estimule o estudo da Matemática, principalmente por aqueles que têm dificuldades com a mesma.

Portanto, toda a melhoria no sistema educacional desse município não tem dependido apenas de um grupo, mas sim, da união de todos aqueles que querem ver a melhoria do ensino (pais, professores, alunos e governantes).

\subsubsection{A Realidade em Barcarena}

Verifiquemos algumas sínteses dos princípios norteadores da Matemática disposto nos PCNs (1996, p. 56):

[...] a Matemática pode e deve estar ao alcance de todos e a garantia de sua aprendizagem deve ser meta prioritária do trabalho docente;

a atividade matemática escolar não é 'olhar para coisas prontas e definitivas', mas a construção e a apropriação de um conhecimento pelo aluno, que se servirá dele para compreender e transformar sua realidade.

Diante das realidades demonstradas sobre o ensino da Matemática e da necessidade de levar um projeto de extensão na área dessa ciência, foi que resolvemos realizar o projeto da OBMEP como projeto de extensão, o qual foi executado no ano de 2008 por discentes da UFPA -Universidade Federal do Pará/Campus Universitário de Abaetetuba. Participaram do projeto dois alunos bolsistas e um voluntário, tendo como coordenador do projeto o professor M.Sc. Sebastião Martins Siqueira Cordeiro, docente desta instituição de ensino superior em parceria com a PROEX/ Pró-Reitoria de Extensão.

A implementação do mesmo ocorreu durante um período aproximadamente de dez meses sendo efetuado na escola Municipal de 
Ensino Fundamental Professor Aloysio da Costa Chaves, tendo como público-alvo alunos de $5^{\mathrm{a}}$ à $8^{\mathrm{a}}$ séries. Os objetivos desse projeto foram: estimular nos alunos o gosto pela Matemática para que sozinhos tenham a facilidade de solucionar problemas matemáticos; despertar nos alunos a curiosidade para pesquisar e a vontade de querer aprender; mostrar que a Matemática não é difícil, e sim que faz parte e está presente no dia a dia do aluno; dar impulso à inclusão social através da propagação do conhecimento.

Este projeto teve como metodologia a realização de encontros, mesas redondas para planejamento e execução. Coordenador, bolsistas e voluntários realizaram uma parceria com o coordenador pedagógico e o diretor da escola, os quais elaboraram uma prova com o objetivo de selecionar alunos para participarem desse acontecimento. Assim, com a conclusão do mesmo, conseguimos despertar no alunado a curiosidade de querer aprender Matemática e, com isso, esses educandos chegaram sozinhos às soluções dos problemas propostos.

Vale ressaltar que a participação e o interesse não foram somente daqueles alunos que haviam sido selecionados, mas também de outros que conseguiram superar algumas dificuldades na aprendizagem. Portanto, entende-se que muitas são as dificuldades quando se busca melhorias para a educação, principalmente no ensino da Matemática; mas apesar dessas dificuldades, procuramos buscar novos rumos para melhorar o desempenho dos alunos nessa disciplina e em outras áreas do saber.

\section{Considerações Finais}

Torna-se evidente o quanto a Matemática é importante para a sociedade. Concluímos que não há como se ter qualidade no ensino dessa área do saber, seja em qual nível de ensino for, sem que estimule tanto docentes quanto discentes.

Nessa linha de pensamento, precisamos conduzir o ensino desta ciência de forma a desenvolver hábitos, precisão, raciocínio dedutivo, manifestações da capacidade criadora e julgamento pessoal, que não apenas levam uma aplicação do cálculo, mas que passam a ser úteis como forma de estudo e como abordagens científicas de outros tantos assuntos ligados à vida profissional e cotidiana do aluno. Além disso, é necessário 
que se estabeleça uma interação do professor-aluno-realidade social. É importante ressaltar que essa interação deve realmente acontecer, para que ocorra, por consequência, a integração da Matemática com as demais áreas do conhecimento, uma vez que o ensino dela deve ser entendido como parte de um processo global na formação do aluno como ser social, pois através desta mudança no processo educacional, esta nova linha de pensamento minimizará o índice de reprovação e evasão desta disciplina.

É dessa forma que a OBMEP vem desenvolvendo um papel fundamental no processo escolar, pois tudo o que foi analisado acima são objetivos que este projeto vem tentando alcançar. Porém, ainda se percebe o desinteresse de alguns profissionais da educação pelo fato de não aceitar as mudanças ocorridas neste novo rumo da matemática. Por outro lado, existem aqueles que apesar das dificuldades vem lutando para que o ensino da matemática possa se erguer dessa turbulência que vem sofrendo.

Todavia, entendemos que a introdução de novas formas de pensar, conhecer e aplicar o conhecimento matemático em nossas escolas não acontecerá de um dia para o outro. Para que as mudanças possam acontecer é indispensável a participação de todos, para que juntos passamos vencer o obstáculo real e nos decidirmos a trilhar um novo caminho. Esse caminho precisa partir de cada um de nós e de todos conjuntamente.

\section{REFERÊNCIAS}

ARANÃO, I. V. D. A Matemática de Brincadeiras e Jogos. $4^{\mathrm{a}}$ Ed.

Campinas: Papirus, 1996. (Séries Atividades).

BRASIL, L. A. S.; LIMA, L. de O. Aplicações da Teoria de Piaget ao

Ensino da Matemática. Rio de Janeiro: Forense/Universitário, 1977.

CUltural, L. Grande Dicionário da Língua Portuguesa. São Paulo: Nova Cultura, 1999.

DIAS, R. Competição Mobiliza Escolas Públicas de Todo o País Desponta como de Novos Talentos. Jornal Ciência \& Tecnologia. Ano 2, n. 6. maio/junho, Brasília, 2005. 
FEYNMAN, R. P. O que é Matemática? site: http//:www.prof2000.pt/ users/folhalcino/estudar/quematm/quemat.atm.28k. Acesso em 22/09/2008.

FREIRE, P. Pedagogia do Oprimido. $17^{\mathrm{a}}$ Ed. Rio de Janeiro: Paz e Terra, 1987.

GONTIGO, C. H. G. Estratégia para o Desenvolvimento em Matemática. Site: http://www.fe.unb.br/linhascriticas/n23/estrategia_ para.html. Acesso em 22/09/2008.

HISTORICO das Olimpíadas. Site: www.geocit.com/olimpmatepara/ hist.html?200815. Acesso em 15/05/2008.

MACHADO, N. J. Matemática e Realidade: análise dos pressupostos filosóficos que fundamento o ensino da Matemática. $5^{\text {a }}$ Ed. São Paulo: Cortez, 2001.

MAZZEU, F. J. C. Uma Proposta Metodológica para Formação Continuada de Professores na Perspectiva Histórico-Social. Cadernos do CEDES, v. 19, Campinas, 1998.

Olimpíada das Escolas Públicas já ultrapassa 3 milhões de Inscrições. site: http://www.agenciat.mct.gov.br/índex.php/content/vien/25930: HTML?toprint=yes. Acesso em 17/07/2008.

PALCINO, C.; COELHO, P. Número: uma introdução à matemática. São Paulo: EDUSP, 1999.

PINHEIRO, N. A. M. Uma reflexão sobre a importância do conhecimento matemático para ciência, para a teconologia e para a sociedade. Ponta Grossa: UFPG, 2003.

RIOS, T. A. Ética e Competência. 11 ${ }^{\mathrm{a}}$ Ed. São Paulo: Cortez, 2001.(Coleção Questões de Nossa Época).

SILVEIRA, M. R. de A. Matemática é difícil? Um sentido préconstruído evidência na fala dos alunos. Site: www. anped.org.br. Acesso em 11/10/2008. 